\title{
Ecosystem Based Adaptation and Disaster Risk Reduction in Indian Himalayan Region of Darjeeling
}

\author{
Raju Sarkar , Saif Alam $^{{ }^{2 *}}$, Sanchit Jain ${ }^{3}$, and Sarthak Saharan ${ }^{4}$ \\ ${ }^{1}$ Department of Civil Engineering, Delhi Technological University \\ Bawana Road, Delhi, India \\ ${ }^{2}$ Department of Civil Engineering, Delhi Technological University \\ Bawana Road, Delhi, India \\ ${ }^{3}$ Department of Civil Engineering, Delhi Technological University \\ Bawana Road, Delhi, India \\ ${ }^{4}$ Department of Civil Engineering, Delhi Technological University \\ Bawana Road, Delhi, India
}

\begin{abstract}
Mountain ecosystems are one of the major landforms in the world. Due to rampant industrialisation and urbanisation, mountainous ecosystem too has bore the brunt of environmental problems such as rising temperature and deglaciation. It has led to disruptions in hydrological functions, impact on forest and biodiversity and also human health implications. Ecosystem based adaptation is a nature based method which centres around environment related concerns and addresses the problem by reducing extreme weather conditions and thus enhancing sustainability and resilience. Darjeeling Himalaya is a mountainous region to the north-western side of the Indian state of West Bengal and has presence of numerous natural calamities such as Earthquakes, Landslides, Cloudbursts, etc. The local administration and the government has taken various measures and policies such as building bye laws, disaster management plan, draft development plan, limit building initiatives in order to act upon environment related hazards. With greater emphasis on EbA approaches to Eco-DRR in the regional policies of Darjeeling, mitigating the impact of climate can be drastically reduced which in turn will lead to Human and Economic Development. The EbA approach helps in (1) enhancing the community adaptive capacity or resilience, (2) improve or regenerate ecosystems to help increase value qualitatively and quantitatively of the produce for local communities and (3) integrating the current produce with market requirements,thereby increasing its economic viability.
\end{abstract}

Keywords: Ecosystem, Disaster Risk, Mountain Geography, Rural Areas, Climate Change

\section{INTRODUCTION}

The Himalaya and the contiguous sloping areas in the northeastern district of the domain of India is together called as Indian Himalaya Region (IHR). It addresses an exceptionally feeble and delicate Mountain Ecosystem [20]. The district, together called as Indian Himalaya Region (IHR), contains various ranges some of which surpass $7000 \mathrm{~m}$ in stature, high knolls, lake bowls, cold deserts, between montane valleys, profound crevasses, snowfields, ice sheets and alluvial fields [22]. A considerable lot of Asia's huge streams which includes Ganga, Indus and Brahmaputra and their endless feeders move through Himalayan reaches which give help to various human developments along their fertile valleys. 
The Indian Himalayan region spans across many states which form the northern boundary of the Indian territory. The forest cover measurements made for the Himalayan states by the Forest Survey of India (FSI) shows that in numerous Northeastern hilly states forest cover has decreased in area during 1997 - 2001, although there is a slight recovery in following years [21].

\begin{tabular}{|l|c|c|c|c|c|c|}
\hline State & $\begin{array}{c}\text { Geographical } \\
\text { Area }\end{array}$ & $\mathbf{1 9 9 7}$ & $\mathbf{1 9 9 9}$ & $\mathbf{2 0 0 1}$ & $\mathbf{2 0 0 3}$ & $\mathbf{2 0 0 5}$ \\
\hline $\begin{array}{l}\text { Arunachal } \\
\text { Pradesh }\end{array}$ & 83,743 & 68,602 & 68,847 & 68,045 & 67,692 & 67,777 \\
\hline $\begin{array}{l}\text { Himachal } \\
\text { Pradesh }\end{array}$ & 55,673 & 12,521 & 13,082 & 14,360 & 14,359 & 14,369 \\
\hline J\&K & 222,236 & 20,440 & 20,441 & 21,237 & 21,273 & 21,273 \\
\hline Sikkim & 7,096 & 3,129 & 3,118 & 3,193 & 3,262 & 3,262 \\
\hline Uttaranchal & 53,483 & 23,243 & 23,260 & 23,938 & 24,460 & 24,442 \\
\hline
\end{tabular}

Fig.1 Distribution of Forest Cover in various states of IHR (in $\mathbf{k m}^{2}$ )

Mountain districts have become inclined to catastrophe with a lopsidedly high occurrence of disasters in contrast with other kinds of environmental system [23]. These mountain ranges are geo-genuinely unsteady and dynamic construction and is exceptionally delicate to slant precariousness. Likewise, the district is set apart by a tough geology, delicate stone conditions, high seismicity, and furthermore high precipitation. These qualities have made the Himalayan ranges profoundly inclined to enormous scope development of structural plates, avalanches, and to the cycles of expulsion of surface. The Himalayas have likewise been exposed to high measure of human mediations. Exercises for work and advancement have developed and expanded the danger and weakness of the locale across the Himalayas.

\section{LITERATURE REVIEW}

The Himalayas give indispensable biological system administrations to the natural and monetary security of individuals living downstream[25]. They are a vault of geographical and agrarian resources and collected wild merchandise, other than being a focal point of social, social, and strict character to countless individuals (Saxena et al. 2001; Birch et al. 2014)[24]. Notwithstanding, the Himalayas are likewise one of the most corruption inclined and delicate mountain ranges on the planet. They are more defenseless because of land reasons, the pressure brought about by the expanding human populace, abuse of regular assets, and impacts of environmental change, which have diverse repercussions on human prosperity (Liu and Chen 2000; Dyurgerov and Meier 2005). The temperature increment is anticipated to be more perceptible in the Himalayan locale (INCCA 2010; Singh et al. 2011) with resultant effects like frosty melts, silt activation, dry spell, avalanches, and blaze floods (Dale et al. 2001; Wulf et al. 2012). These effects have brought about decreased usefulness of regular and human changed environments, loss of the travel industry income, framework and food and water security for the networks living in the area (WHO 2012; Badola et al. 2014; Smith 2014)[1].

The idea of environment administrations has turned into a significant model for connecting the working of biological systems with human prosperity (Fisher et al. 2009)[2]. In any case, even as interest for environment administrations is developing, human activities are reducing the ability of biological systems to fulfill these needs. Sound normal asset the board methodologies can frequently invert biological system debasement and upgrade the commitments of environments to human prosperity (MEA 2005). As of late, a huge and quickly developing assortment of examination

\begin{tabular}{lll}
\hline (c) 2022, IJSREM & www.ijsrem.com & DOI: 10.55041/IJSREM11671
\end{tabular} 
has been trying to recognize, portray and esteem environment labor and products (Bagstad et al. 2013) and plan ways of guaranteeing their constant arrangement[4]. Current biological system based methodologies have proposed that strategies and measures be embraced that consider the job of environment administrations in lessening cultural and natural weakness through multi-sectoral and staggered approaches (Andrade et al. 2011). Market analysts, tree huggers, and lobbyists have proposed different sorts of strategy blend, contending that 'solitary instrument' or 'singleprocedure' approaches are off track and when utilized independently neglect to address complex reasons for environment administration debasement (for example Gunningham and Sinclair 1999; Ring and Schroter-Schlaak 2011)[3].

\section{EbA and Eco-DRR}

EbA centers around environment related regular perils, long haul means changes in environment and future vulnerabilities. For instance, it can prompt ascent in ocean levels and can add to change precipitation designs. These all includes an expansive arrangement of strategies to adjust to the environmental change. It includes biological system the board and the executives of its administrations to assist with lessening the weakness of individuals to the negative effects of the environmental change. For example, utilizing the technique for woodland insurance to assist with water maintenance in areas that are becoming drier. Eco-DRR (Disaster Risk Reduction) - It is a procedure for diminishing peril to typical risks by thwarting settlement and improvement in a disaster slanted districts by using an overall coordinated organic framework as a trademark pad to get people similarly as real properties in any area. Perils can join both climate as well as non-climate related dangers. For instance, tremors, volcanoes, landslides, waves. Intersection of EbA and Eco-DRR-This incorporates the executives of environment hazard, implying environment related normal risks like tempests, floods, dry spell, avalanches, fire and so on for example mangrove reclamation or salt bogs rebuilding for waterfront assurance from floods of tempest.

\subsection{Link between Disaster, Climate and Development}

India's unique geo-climatic conditions leaves it exposed to a variety of disasters, including floods, cyclones, earthquakes, and drought. Around 58.6\% of the country's landmass is sensitive to earthquakes; $12 \%$ of the landmass is subject to floods; and 68 percent of the country's agricultural area is vulnerable to droughts. A multitude of socioeconomic issues, such as poverty, inequality, expanding populations, precarious livelihoods, and the growing economy's developmental priorities, all contribute to India's vulnerability to disaster risk. Direct losses from catastrophes in India cost alomost 2\% of the India's GDP and over 12\% of the union government's income on average (World Bank 2003). Floods are responsible for annual losses in the United States, costing \$7 billion per year (UNISDR 2015)[6]. Between 1980 and 2017, India saw 278 flood disasters, resulting in a total economic loss of $\$ 58.7$ billion and affecting over 750 million people throughout the country (UNISDR \& CRED 2018). The losses experienced by disasters, such as deaths, injuries, and destruction of buildings/infrastructure, are primarily included in these estimates of human and economic costs of catastrophes. The indirect effects of disasters on communities are frequently understated or unaccounted for. Hazard informed improvement orchestrating can pass on climate and disaster change shortcomings. There are different public ventures and plans which can go probably as potential area centers for mainstreaming fiasco and climate related concerns at both public and sub-public levels. These advancement activities can further develop strength of organizations against calamities and climatic risks by guaranteeing permission to economical work and fundamental administrations like clinical consideration, preparing, sanitization, water supply, etc; thus, diminishing weaknesses and updating limits of networks to withstand the fiasco and ecological change impacts[5]. 


\section{MOUNTAIN ECOSYSTEM}

It is broadly acknowledged that the debasement of mountain environments isn't any territorial issue yet a worldwide one. The Himalayas which are endowed with an extraordinary and quiet normal brilliance, plentiful assets, enduring waterways, other than being a storage facility of uncommon types of verdure, comprises one of the most undermined environments of the world. Given its delicate land profile, Himalayas is defenseless against numerous ecological perils and calamities of various kind, nature, and extent. Some among them incorporate quakes, avalanches, snow torrential slides, floods, trash streams, pandemics, and flames. These have been the most widely recognized reasons for death, harm, and obliterations in the Himalayan district [7-8].

\subsection{Impact of Climate Change on Mountain Eco-System}

The mountain ecological systems impact the air course altogether; however, they additionally show a lot of variety in the nearby climatic examples. In this manner, mountain biological system is probably going to get impacted the most in case there is any worldwide environmental change [10]. The effect of environmental change on mountain ecological system but can't be anticipated with sensible precision because of absence of long haul and timetable examinations [28]. In these areas even a slight change can possibly have a huge effect, especially in minimal conditions that are under pressure. A portion of the ordinarily noticed effects are:

\subsubsection{Impact on Glaciers}

Himalayan frosty masses have a locale around $23,000 \mathrm{~km}^{2}$. It is most likely the greatest space of ice sheet set aside new water isolated from the polar (north and south) locale [11]. Chilly masses are an eventual outcome of climate and natural change. It is truly figured as certifiable thermometer of a risky air deviation. Audits coordinated for satellite imaging and ground assessments done by Indian Space Research Organization's Space Application Center (SAC) has set up the ice sheets have diminished from 2,077 $\mathrm{km}^{2}$ to $1,628 \mathrm{~km}^{2}$ in Himachal Pradesh alone - an overall deglaciation of $21 \%$ in forty years. As demonstrated by SAC as much as 127 ice sheets of under $1 \mathrm{~km}^{2}$ size have lost $38 \%$ of their geological locale beginning around 1962[27]. The greater ones, which are little by little getting separated into extra pieces, has withdrawn by however much $12 \%$ which is upsetting. Experiences on cold decline in IHR is open for only latest 150 years [13]. It reveals that the Himalayan frosty masses are pulling out at a typical speed of 18-20 $\mathrm{m} \mathrm{yr}^{-1}$. The pace at which some of the significant Himalayan ice sheets are retreating is introduced beneath:

\begin{tabular}{|l|c|c|c|}
\hline Name of Glacier & Period(in years) & Recession (in m) & $\begin{array}{c}\text { Average } \\
\text { rate(m/yr) }\end{array}$ \\
\hline Milam Glacier & 108 & 1350 & 12.50 \\
\hline Pindari Glacier & 121 & 2840 & 23.4 \\
\hline Gangotri Glacier & 29 & 580 & 20.00 \\
\hline Tipra Bank Glacier & 26 & 325 & 12.50 \\
\hline Dokriani Glacier & 29 & 480 & 16.50 \\
\hline Chorabari & 41 & 238 & 5.80 \\
\hline Shankulpa & 76 & 518 & 6.80 \\
\hline Poting & 51 & 262 & 5.13 \\
\hline Glacier no-3 Arwa & 24 & 198 & 8.25 \\
\hline Bara Shigri & 07 & 219 & 31.28 \\
\hline Chhota Shigri & 03 & 54 & 18.5 \\
\hline Sonapani & 52 & 899 & 17.2 \\
\hline Kolai & 49 & 800 & 16.3 \\
\hline Zemu & 07 & 193 & 27.5 \\
\hline
\end{tabular}

Fig.2 Rate of Glacial Recession 


\subsubsection{Disruptions in Hydrological Functions}

Expansion in encompassing temperature can have solid impact on neighborhood climate design. It is anticipated that there would be a vertical change in different climatic zones with slight expansion in temperature. Likewise, there is an expanding proof that colder time of year precipitation as snow fall has declined throughout the long term. Expansion in glacial mass softening is probably going to build overflow and frigid lake explosion floods. Decrease in the Cryosphere can likewise modify upstream hydrology, stream, essential efficiency, and mountain cultivating. Different outcomes of diminished hydrological capacities incorporate deficiency of drinking water, decrease in rural and hydropower creation. Effect of diminished catchment capacities in IHR is probably going to be undeniably more genuine on urban communities, cities and towns which lie on the downstream section including Himalayan lower regions that are dependent totally (or somewhat) on streams and waterways of these mountains [12].

\subsubsection{Implication on Human Health}

A portion of the consequences for human wellbeing are expanded encompassing temperature. It will then, at that point, cause warm pressure, bringing about inconvenience, physiological pressure and medical affliction. The recent concern of nature of water is presumably going to be furthermore weakened by ecological shift. The chances of spread of water-borne contaminations is going to augment. Without a doubt, even as of now, induction to safe drinking water is confined in the Himalayan Region. Ecological shift will in like manner impact in transmission of overwhelming ailments by dreadful little creatures, for instance vector-borne ailments like dengue, wilderness fever, and schistosomiasis. Such contaminations are vulnerable to the temperature similarly as to the land use variations [14].

\subsection{Measures to Deal with Impacts}

India is a signatory to the Kyoto Protocol. Thus it is resolved to abide by significant standards as referenced in the National Environmental Policy, NEP 2006[20]. However conformity to standards wherever should emphatically affect the mountain climate, the mountain individuals themselves should get very much adjusted and reasonably furnished to manage the resultant outcomes of environmental change[17]. This would require a progression of mechanical intercessions upheld by logical exploration and financial variations. It will be basic for accommodating the discernments on environmental change issues as seen by the specialists, strategy producers the mountain individuals, a larger part of whom are too poor to even consider making any such strides[16].

\subsubsection{Establishing Networks of Meteorological Station Across the Region}

Establish framework for environmental change research, particularly an organization in the Indian Himalayan Region of meteorological stations, and start incorporated review on the climatology through facilitated exertion among different foundations, gather specialized (determining, observing, planning, and preparing for experts) political and monetary help for the said program[30]. Models should be created utilizing composite information to foresee the progressions and measure their effect in the different environments of the IHR for better administration procedures[15].

\subsubsection{Increase Monitoring of Glacial Recession}

Glacial masses in chosen areas inside the IHR, for example, those having fast deglaciation as of late should be checked on ceaseless reason for deciding pattern of the effect of worldwide environmental change. Stretch out examinations on ice sheets even to Eastern Himalaya[31]. 


\subsubsection{Disease Surveillance}

With the movements in the climate of mountain regions, a couple of vector-borne sicknesses will undoubtedly move to the higher heights. As such there is a sincere need to begin facilitated disease perception and deciding system for spread of vector borne sicknesses across the IHR[29].

\subsubsection{Integration for Development of Mountain Region}

Mountain is a significant wellspring of water, energy and organic variety. They are a wellspring of various assets like minerals, backwoods items and horticultural items. Likewise they are utilized for diversion reason. Mountain conditions are fundamental for the endurance of the worldwide biological system as they address mind boggling and interrelated environment of our planet. Mountain biological systems are, in any case, quickly evolving. They are defenseless against expanding soil disintegration, avalanches and quick loss of territory and hereditary variety. On the human side, there is unavoidable poverty among mountain tenants and besides there is loss of local data. Thusly, most overall mountain districts are experiencing environmental debasement. Thusly, genuine organization of mountain resources and monetary improvement of people justifies a brief movement [18-19].

\begin{tabular}{|l|c|c|c|}
\hline State & $\mathbf{2 0 0 4 - 0 5}$ & $\mathbf{2 0 0 9 - 1 0}$ & $\mathbf{2 0 1 1 - 1 2}$ \\
\hline Arunachal Pradesh & 31.4 & $\mathbf{2 5 . 9}$ & 9.20 \\
\hline Assam & 34.4 & 37.9 & 31.98 \\
\hline Himachal Pradesh & 22.9 & 9.5 & 8.06 \\
\hline Jammu \& Kashmir & 13.1 & 9.4 & 10.35 \\
\hline Manipur & 37.9 & 47.1 & 36.89 \\
\hline Meghalaya & 16.1 & 17.1 & 11.87 \\
\hline Mizoram & 15.4 & 21.1 & 20.46 \\
\hline Nagaland & 8.8 & 20.9 & 18.88 \\
\hline Sikkim & 30.9 & 13.1 & 8.19 \\
\hline Tripura & 40.0 & 17.4 & 14.05 \\
\hline Uttarakhand & 32.7 & 18.0 & 11.26 \\
\hline India & 37.2 & 29.8 & 21.92 \\
\hline
\end{tabular}

fig.3 Percentage of Population below Poverty Line (Tendulkar Method): Indian Himalayan States

\subsubsection{Addressing Poverty and Improving condition of women and children in Mountain Re- gions}

Consideration of the fundamental reasons behind poverty in mountainous areas and women drudgery is of utmost urgency. It cannot be attended by looking everything through a conservationist glass. A balance must be struck between conservation of environment and development. Population which is below the poverty line in the mountain regions are greater than other parts of the country and its greatest impact is upon women and children in mountain areas, as majority of the able-bodied adults migrate out of these regions in search of livelihood. Also, the agriculture of these regions is at subsistence levels [26].

\section{DARJEELING}

The Himalayas in the Darjeeling is a rapidly urbanizing area in northeastern locale of India, continuously introduced to ordinary risks like shakes, torrential slides, and changing instances of precipitation in view of ecological change. This paper explores the marvelous underpinnings of fiasco danger creation in the region according to the viewpoint of cataclysm value. We the design in the Darjeeling Himalayas using the improvement of multi praised considerable 
constructions as our object of assessment and considering data assembled from gatherings, plans and technique records, and part insight. This consistent assessment shows that a standard course of action of significant worth is a critical beginning stage for evaluating improvement processes and their commitment to catastrophe hazard, yet moreover illuminates how contemplations of calamity esteem are fascinating to express spots. By using such a construction, changed to fit explicit settings and conditions, we acknowledge that metropolitan improvement specialists can develop a more clear and taught technique for surveying the value with respect to their work.

\subsection{Hazards and Climate Change}

With its unsafe mountain inclinations and fast streaming streams, the Darjeeling Himalayas is introduced to different geologic and hydrologic hazards. During the tempest season, weighty precipitation produces streak flooding and triggers torrential slides, rockfalls, and other soil chances. Torrential slides, a trademark component of mountain conditions exacerbated by anthropogenic activities, consistently cost lives, upset system structures, and lead to enormous property mischief and land hardship. In 1968, for instance, just about 1000 millimeters of storm fell on the area in just three days, which made cataclysmic flooding and north of 20,000 torrential slides that killed enormous number of people and demolished homes, associations, and establishment like roads and platforms.

The district is also at high risk of tremors. As shown by the Geologic Survey of India, the Darjeeling Himalayas is by and large arranged in seismic zone IV, which has a bunch of encounters and partiality for gigantic and hurting events. In 2011, a 6.9 significance seismic quake with a point of convergence in bordering Sikkim killed 111 people and hurt or destroyed a couple thousand designs. Seismologists acknowledge that the district is sensible past due for a critical shudder of 8.0 significance or more noticeable, with conceivably disastrous results.

\subsection{Risk}

For the Darjeeling Himalayas, and for other urbanizing areas facing colossal risks from normal dangers, a significant request regarding catastrophes and progression has to do with the value of these risks. Many records of environmental value use the aftermath of unequivocal disasters, with the upside of knowing the past and the variations of the risk scene recognized, as their fundamental wellspring of verification. In this article, we battle that review the peril that stores up in the manufactured environment before disasters occur, to understand the value of the metropolitan progression processes by which that danger is made and shared.

\subsection{Current Guidelines}

District Nodal Officer (Environment): Division of Biodiversity and Environment has undertaking to make approaches, techniques, regulation, and rules to shield uprightness biodiversity, biological systems, and economical improvement in Darjeeling area [31].

The key jobs include Facilitation in creating arrangements, procedures, regulation, rules, plans and program in the region. Research and improvement. Capacity building and bringing issues to light on biodiversity, biological system, biosecurity, climate. Coordinate with concerned service and office for the administration of biodiversity, environments, and bio-wellbeing. Develop and fortify collaboration with improvement accomplices, common society, private area, the scholarly community, and other applicable partners to help preservation and the executives of biodiversity, biological systems, and biosecurity [25].

District Level Biodiversity Management Committee (DBMC) - Region level BMC is an approach making body reconstituted in January 2021 to empower feasible turn of events and furthermore to guarantee financial, natural, social, and social equilibrium inside Darjeeling region. DBMC involves 11 individuals alongside various squares, regions, and panchayats level Biodiversity Management Committees inside the locale. It is led by the District Magistrate, Darjeeling. 


\section{DISASTER MANAGEMENT}

2030 been set as the end year for long-term activities in order to align the NationalDisaster Management Plan with post-2015 international accords. To synchronize the National Disaster Management Plan with the post-2015 peaceful accords, 2030 has been imagined as the closure year for long haul activities. The following agreements and steps are taken up.The government adopted three key international disaster management agreements in 2015:Sendai Framework for Disaster Risk Reduction (SFDRR) in 2015; Sustainable Development Goals (SDGs) (2015to30) in 2015;Paris Agreement on Climate Change at the UNFCCC 21st Conference of Parties (COP-21). Following documents are used_NDMA and respective inputs from various state govts, SDMA;National Disaster Management Plan (NDMP) in 2016 and 2019;D1saster Management Act(DMA) ,2005;Darjeeling disaster management plan has been extensively used.

The Indian Himalayan Region (IHR) stretches across 2,500 kilometres between the Indus and Brahmaputra River systems, and covers an area of about 5.3 lakh square kilometres. While glacial lake risks and distributions are studied in numerous glaciated places across the world, the Indian Himalayas have received comparatively little attention. The Himalayan region of India has a unique geographical entry into our nation, with a vast range of terrain, geology, soil, climate, flora and wildlife, and distinct ethnic groups with diverse socio-cultural traditions.

Risk mitigation techniques in the Himalayan area are primarily meant to mitigate or restrict the negative consequences of previously existing catastrophe risks using a mix of structural and non-structural measures.Once the area has been classified as hazard prone, it is critical that the government and the community take the steps outlined above. The mitigation strategy may differ depending on the key dangers identified, based on this methodology.

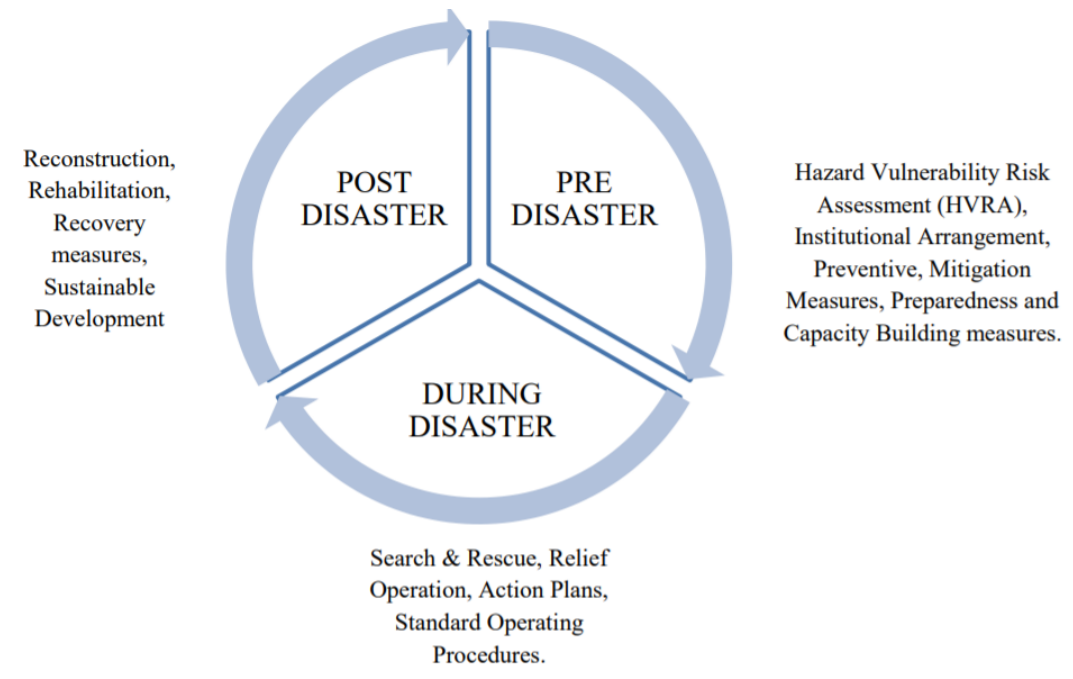

fig.4 : District Disaster management plan Darjeeling 2020-21

\subsubsection{EARTHQUAKE}

The Himalaya Mountains due to tectonic plate movement that has led to an increase in its height. Measures taken up in Darjeeling (wrt.earthquakes) as per the NDMA Act:District administration assured that multi-hazard-resistant measures are included in the development and implementation of social housing projects Ensuring that all applicable construction codes are followed.Strengthening and earthquake retrofitting as directed by the Ministries.Keeping a strict Vigil and safety audit of essential infrastructure and lifeline buildings in the district Ensuring effective implementation along with the incorporation of social audits in the district. 


\subsubsection{CLOUDBURST}

Cloudburst is a short-term severe precipitation event that happens over a limited region and produces $10 \mathrm{~cm}$ or more rainfall in an hour.Raindrops are shipped upwards by the air current as opposed to falling as precipitation when immersed mists can't create downpour because of the vertical development of warm flows of air coming about to unnecessary buildup. Raindrops become too heavy to be transported aloft after a certain point and fall together in a flash.

As per NDMA, SDMA guidelines with respect to Cloudbursts, construction operations along river banks must be regulated, with specific attention paid to water levels after severe rains; Constricting and regulating water flow through strengthening embankments, barrages, and dams;Providing appropriate resources to re-energize the SDMA (funds and personnel);Localized planning that takes into account the region's ecological fragility and involves local populations;Preserving the purity of eco-sensitive zones by regulating infrastructure developments;IMD's improved forecasting and use of new technologies to monitor and anticipate extreme weather occurrences can help with early warning, evacuation, and preparedness;Disaster management and prevention are incorporated into the development planning process.ISRO's Space Application Centre (SAC) has created a model for heavy rainfall/cloud burst alarm to mitigate the effects of a cloud burst.It is now in pilot mode, but if its efficacy is established, it will go a long way toward saving lives.

\subsubsection{LANDSLIDE}

A landslide is a disaster phenomenon that occurs when a pile of rock, rubble, or dirt slides down a hill. NLRM (National Landslide Risk Management Strategy,2019) includes hazard mapping, monitoring, and early warning systems, as well as other areas of landslide catastrophe risk reduction and management.It involves landslide stabilisation and mitigation, as well as awareness campaigns, capacity building, training, legislation, and policies.Promotion and the adoption of landslide rehabilitation and mitigation strategies that are effective.Creating institutional capacity limit and preparing for geoscientists, specialists, and organizers is needed for viable administration of threat[31].

Following NDMA AND SDMA guidelınes have been 1ncorporated in Darjeelıng disaster management plans such as:-Recharging the ground water and benefitting the environment by storing excess water in catchment regions to decrease the damage from flash floods.In the catchments, creation of dig runoff collection ponds. Plant fuel and fodder trees on all common lands. Planting grass cover in barren places, particularly on slopes, is an important component of an integrated watershed management programme[31]. Grazing should be strictly controlled. Better grasses can be planted when the region has been totally protected from grazing. Use surface vegetative cover to shield the ground from the pounding action of raindrops, bind soil particles, and slow the flow of water. Other darjeeling specific measures being taken up by the district administration such as the department undertakes the following functions:Upgradation and Preparation of the annual.DDMP;Directing the concerned departments and stakeholders on calamity preparedness measures; Releasing grants for the dead or ex gratia amount to the victims[32].

\section{POLICIES INCORPORATING EbA and Eco-DRR}

Disaster Risk Reduction outlines a huge piece of the current peril decrease measures [21]. The Yokohama Strategy (1994), the Indian Disaster Management Act (2005), Hyogo Framework for Action (HFA) (2005 2015) and Administrative Reforms Commission Report (2006) of the Government of India have ceaselessly settled the significance of calamity decline. In accordance with these frameworks and rules, the Darjeeling area has also accepted a movement of measures to diminish risk in the spaces under its ward. The activities can immediately be assigned follows:

Building Byelaws that gives a comprehensive managerial framework to the advancement of constructions inside Darjeeling common district. Disaster Management Plan targets propelling a "culture of availability" through proactive disaster the chiefs' extents of "orchestrating, status and expectation" for making "fiasco flexible Darjeeling with 
outright risk decline as the essential noticing limit in each developmental theory and drives to ensure viable new development [27]."

Draft Development Plan is a significant instrument for consolidated arrangement and changed development and gives a functional technique towards organizing the disaster the board stresses with progression orchestrating. Limit Building Initiatives Capacity building is a huge piece of cataclysm preparation. Concerning the Darjeeling Municipal district, the Municipality, NGOs, Civil Defense Department, and various social events have taken measures to improve and build the neighborhood with respect to better fiasco status. These social occasions, in any case, don't work in isolation; rather they have hoped to enhance their undertakings through cooperation and linkages. The Municipality, in a joint effort with the Civil Defense Department and NGOs having a few aptitudes in fiasco the chiefs like Red Cross and Anugyalaya and samaj, has begun measures for limit collecting that fuse honing the neighborhood the calamity, planning for rescue and help and developing neighborhood through courses and studios [25].

\section{CONCLUSION}

Eco-DRR and EbA play an important role, so as to reduce the vulnerability to climate change of any particular region. The frameworks discussed above thus proposes an approach for the facilitation of evaluation and monitoring of interventions to help fight various inequalities, risks associated with climate change. Thus, in this hour, it becomes even more important to study Disasters, risks associated with them along with their mitigation. It indicates that a comprehensive methodology needs to be adopted for design, implementation, monitoring, evaluation, and review of such interventions. The frameworks discussed above are not expected to be prescriptive in nature and therefore can be applied flexibly as per the requirement and conditions in any given region.

Based on the analysis above of the policies and procedures in place in Darjeeling, it does not fully accommodate the upcoming environmental hazards and Darjeeling should make a standardized department for EbA and Eco-DRR related enquiries. Pilot studies for execution of both the concepts should take place region wise and collective data should be used in making new action plans for betterment of the ecosystem of Darjeeling. With the implementation of Ecosystem based approaches, it will benefit various sectors. Due to such policies in the regions of Darjeeling, water, agriculture, forests sectors will be conserved which will further lead to improvement in energy, health and tourism. Due to these advantages of EbA, it is imperative to explore these opportunities and invest for further study on ecosystem-based approaches to adaptation. It demands inputs of cross sectoral policy makers for policy formulation to achieve an increased level of sustainability and resilience in the mountain ecosystem.

\section{References}

[1] S. Besky, "The Land in Gorkhaland," Environ. Humanit., vol. 9, no. 1, pp. 18-39, 2017, doi: 10.1215/22011919-3829118.

[2] B. Zutshi, Manipur flood 2015: Preparedness and disaster risk reduction strategies. 2018.

[3] S. Singh, S. M. Tanvir Hassan, M. Hassan, and N. Bharti, "Urbanisation and water insecurity in the Hindu Kush Himalaya: Insights from Bangladesh, India, Nepal and Pakistan,” Water Policy, vol. 22, pp. 9-32, 2020, doi: 10.2166/wp.2019.215.

[4] R. Seidler and K. S. Bawa, "Ancient risks, current challenges in the Himalayas," Econ. Polit. Wkly., vol. 51, no. 41, pp. 63-67, 2016.

[5] S. Bera, B. Guru, R. Chatterjee, and R. Shaw, "Geographic variation of resilience to landslide hazard: A household-based comparative studies in Kalimpong hilly region, India," Int. J. Disaster Risk Reduct., vol. 46, no. December 2019, p. 101456, 2020, doi: 10.1016/j.ijdrr.2019.101456.

[6] E. Brink et al., "Cascades of green: A review of ecosystem-based adaptation in urban areas," Glob. Environ. Chang., vol. 36, pp. 111-123, 2016, doi: 10.1016/j.gloenvcha.2015.11.003.

[7] T. K. Datta, "Advantages, Constraints And Key Success Factors In Establishing Origin- And TraditionLinked Quality Signs : The Case Of Darjeeling Tea , India," Evolution (N. Y)., 2009.

[8] A. CHHETRI and L. TAMANG, "Decentralization of Water Resource Management: Issues and Perspectives Involving Private and Community Initiatives in Darjeeling Town, West Bengal," Ann. Natl. 
Assoc. Geogr. India, vol. 39, no. 2, pp. 240-255, 2019, doi: 10.32381/atnagi.2019.39.02.6.

[9] L. Dorren and M. Schwarz, Ecosystem-Based Disaster Risk Reduction and Adaptation in Practice, vol. 42, no. December. 2016.

[10] F. C. Godoi, S. Prakash, and B. R. Bhandari, "Final report Final report," Rev. 3D Print. potential red meat Appl., no. 23 February 2021, pp. 1-61, 2021.

[11] S. Bhattacharya, G. Ghosh, T. Banerjee, S. Goswami, and P. Das, "Socio-Environmental Survey of an Ecologically Important Hamlet of Darjeeling District West Bengal, India," Int. Lett. Nat. Sci., vol. 33, pp. 51-72, 2015, doi: 10.18052/www.scipress.com/ilns.33.51.

[12] B. K. Shah, V. Kedia, and R. K. Jha, "Integrated Vendor-Managed Time Efficient Application to Production of Inventory Systems," Proc. 6th Int. Conf. Inven. Comput. Technol. ICICT 2021, pp. 275-280, 2021, doi: 10.1109/ICICT50816.2021.9358504.

[13] P. Chaudhary et al., "Consistency of local perceptions of climate change in the Kangchenjunga Himalaya landscape," Curr. Sci., vol. 101, no. 4, pp. 504-513, 2011.

[14] J. A. Klein et al., "An integrated community and ecosystem-based approach to disaster risk reduction in mountain systems," Environ. Sci. Policy, vol. 94, no. December 2018, pp. 143-152, 2019, doi: 10.1016/j.envsci.2018.12.034.

[15] H. Sandhu and S. Sandhu, "Linking ecosystem services with the constituents of human well-being for poverty alleviation in eastern Himalayas," Ecol. Econ., vol. 107, pp. 65-75, 2014, doi: 10.1016/j.ecolecon.2014.08.005.

[16] M. Ghosh and S. Ghosal, "Living with insecurity: A critical examination of the environmental problems linked with social problems in rural west bengal, india," Rom. J. Geogr., vol. 63, no. 1, pp. 53-64, 2019.

[17] A. Shroff, B. K. Shah, A. Jha, A. K. Jaiswal, P. Sapra, and M. Kumar, "Multiplex Regulation System with Personalised Recommendation Using ML," Proc. 5th Int. Conf. Trends Electron. Informatics, ICOEI 2021, pp. 1567-1573, 2021, doi: 10.1109/ICOEI51242.2021.9453005.

[18] B. K. Shah, V. Kedia, R. Raut, S. Ansari, and A. Shroff, "Evaluation and Comparative Study of Edge Detection Techniques," vol. 22, no. 5, pp. 6-15, 2020, doi: 10.9790/0661-2205030615.

[19] B. K. shah, A. Kumar and A. Kumar, "Dog Breed Classifier for Facial Recognition using Convolutional Neural Networks," 2020 3rd International Conference on Intelligent Sustainable Systems (ICISS), 2020, pp. 508-513, doi: 10.1109/ICISS49785.2020.9315871.

[20] J. P. Basu, "Climate change vulnerability and perception of different occupational groups of household in the hill regions of Darjeeling district, West Bengal," Indian J. Ecol., vol. 47, no. 1, pp. 248-258, 2020.

[21] J. A. Rather and M. S. Bhat, "..... A .... Research Periodic Evaluation of Long Term Precipitation Trends in Eastern Middle Himalayas : A," no. December, 2020.

[22] B. P. Resurrección et al., The Hindu Kush Himalaya Assessment. Springer International Publishing, 2019.

[23] S. Besky, "Rural Vulnerability and Tea Plantation Migration in Eastern Nepal and Darjeeling," Himal. Res. Pap. Arch., pp. 1-21, 2007, [Online]. Available: http://hdl.handle.net/1928/3304.

[24] R. Seidler, "Seidler et al . 2018 - Progress on integrating climate change adaptation and disaster risk reduction in South Asi ...," 2018.

[25] B. K. Shah, A. K. Jaiswal, A. Shroff, A. K. Dixit, O. N. Kushwaha, and N. K. Shah, "Sentiments Detection for Amazon Product Review," 2021 Int. Conf. Comput. Commun. Informatics, ICCCI 2021, 2021, doi: 10.1109/ICCCI50826.2021.9402414.

[26] E. Sharma et al., The Hindu Kush Himalaya Assessment. Springer International Publishing, 2019.

[27] Reliefweb.int, "Using mobile phone technologies for Disaster Risk Management: Reflections from SHEAR, June 2021 - World | ReliefWeb," no. June, pp. 1-29, 2021, [Online]. Available:

https://reliefweb.int/report/world/using-mobile-phone-technologies-disaster-risk-management-reflectionsshear-june-2021.

[28] M. Kumar, A. Bhatia, P. Gupta, K. Jha, R. K. Jha, and B. K. Shah, "S IGN L ANGUAGE A LPHABET R ECOGNITION U SING,” no. Iciccs, pp. 1859-1865, 2021.

[29] A. Snyder, "Shortage in the Mountains of Plenty : Water Supply in Mountain and Hill Cities throughout the Hindu-Kush Himalayan Region," 2014.

[30] M. Chamling and B. Bera, "Spatio-temporal Patterns of Land Use/Land Cover Change in the BhutanBengal Foothill Region Between 1987 and 2019: Study Towards Geospatial Applications and Policy Making," Earth Syst. Environ., vol. 4, no. 1, pp. 117-130, 2020, doi: 10.1007/s41748-020-00150-0.

[31] V. Lo, Synthesis report on experiences with ecosystem-based approaches to climate change adaptation and disaster risk reduction, vol. Technical, no. 85. 2016. 
[32] V. Kedia, S. R. Regmi, K. Jha, A. Bhatia, S. Dugar, and B. K. Shah, "Time Efficient IOS Application for CardioVascular Disease Prediction Using Machine Learning," Proc. - 5th Int. Conf. Comput. Methodol. Commun. ICCMC 2021, no. Iccmc, pp. 869-874, 2021, doi: 10.1109/ICCMC51019.2021.9418453. 